\title{
3. Knowledge Moves: regulation and the evaluation of Portuguese schools
}

\section{Natércio Afonso and Estela Costa}

\section{Introduction}

This chapter explores the role and function of knowledge as a regulatory instrument. It examines how knowledge is produced and reproduced, thus performing its regulatory role within a specific policy process. It does so by means of a case study of the design and implementation of a programme of external evaluation of public schools in Portugal.

In a general sense, regulation is a form of policy. It is an expression of power, simply construed: it constitutes an attempt by one player to structure the behaviour of others. Now, in highly centralised countries like Portugal, the term 'regulation' is associated with the debate on reform and modernisation of public administration. It is imbued with a sense of governance rather than government, a 'new public management' where $a$ priori direct control of procedures is replaced by a posteriori remote control based on results (Barroso, 2005). In international context, Portugal offers a good example of the rise of 'postbureaucratic' forms of regulation in education policy (Barroso, 2000; Maroy and Dupriez, 2000; Maroy, 2008).

Evaluation functions as a form of regulation in very specific ways. First, it shapes the behaviour of actors by measuring it against some standard, usually a specific level of achievement or a notion of best practice. This makes it very different from traditional bureaucratic forms of regulation, in which actors are governed by the application of rules. In evaluation, in other words, behaviour is considered wrong not because it is illegal, but because it is not effective. Second, and of particular interest here, evaluation entails the production and circulation of new knowledge and information: guidelines are drafted and examples of best practice set; data is collected and analysed and performance compared and assessed.

Third, because information about organizational and professional performance is collected and processed by actors themselves, often according to categories and standards set by their peers, regulation by evaluation is very often a process of self-regulation. In this way, evaluation forms an essential part of the cognitive framework within which the autonomy of actors such as these is exercised: the function of regulation is not simply to manage what they do, but to manage the way they think about what they do.

The empirical data used here was derived from the analysis of documents, primarily from the Portuguese Inspectorate's online database (which includes policy statements, planning documents, operational guidelines, school reports, national reports and conference minutes). In order to probe and expand on the information they provide, interviews were conducted with an evaluation team, 
including two field inspectors and one external evaluator, who was a retired teacher. Likewise, a case study was carried out in a school where an external evaluation had recently been carried out. Information was collected from a range of interviewees: from the director of the school and her staff management, and four department coordinators.

\section{The making of the school evaluation programme}

In 2005, following a landslide victory in parliamentary elections, a new government came to power in Portugal. The newly appointed Education Minister - an outspoken sociology professor - stressed the need to adopt evidence-based policy measures to rationalise and modernise the education system. A key element in this strategy was reinforcing and refining the system's evaluation structures, to produce data to support policy decisions.

As part of this strategy, a new model for the evaluation of public schools was announced. A six-member team of experts - four academics and two senior civil servants from the Ministry - commissioned the design of the model. This School Evaluation Working Group (SEWG) produced and tested an evaluation framework. The framework included indicators, criteria, data collection guidelines, reporting templates and scripts for conducting meetings, and drew on theoretical and institutional references from the scientific literature as well as the professional know-how of inspectors and evaluators. The Ministry's Inspectorate General for Education (IGE) was then charged with putting the new policy into practice from 2006. By 2010-11, every public school was to be subject to evaluation: this required a school self-evaluation document to be produced, an undertaking that entailed collecting and analysing a prescribed set of data; organising the evaluation team's school visit, including meetings and interviews with specific stakeholders, and preparing a final report to be published on the Inspectorate website.

But how did the SEWG know how to go about evaluating schools? Why was the programme of school evaluation deemed appropriate or even necessary? And what were the ideational and cognitive components of this new regulatory regime? They were essentially of two kinds: a technocratic understanding of evaluation combined with policy models from other countries.

The members of the School Evaluation Working Group brought together different fields of expertise and experience of different sectors. The group comprised six individuals with diverse academic qualifications and professional backgrounds in higher education and public administration. Pedro Guedes de Oliveira, José Fernando Oliveira and Maria Antónia Carravilla were each professors or researchers at the University of Porto; Pedro Guedes de Oliveira and José Oliveira held doctorates in Electrical and Computer Engineering, and Carravilla in Production Planning. Cláudia Sarrico was professor at the University of Aveiro, having worked in management in the social and legal sciences and as a consultant in operational research, while Maria do Carmo Clímaco was a former English teacher with experience in higher education, who had served as Inspector General of Education. Both held PhDs in Social Policy 
from English universities. Finally, José Maria Azevedo was a senior government official with postgraduate qualifications in Education, Development and Social Change and in Management and Public Administration. He was also a former Inspector-General of Education and was now providing strategic scientific advice to the Office of the Minister of Education in the Portuguese government.

Despite the diversity of their backgrounds, all the members of the Working Group had both national and international expertise in evaluation (see Barroso et al, 2008, p 114). Thus, of the three engineering professors, one was involved in the evaluation of public sector R\&D - Pedro Guedes de Oliveira, the group's coordinator; another worked in the application of decision support methodologies for assessment and management processes in a university - José Fernando Oliveira; and the third, Maria Antónia Carravilla, was involved in projects to support decision making in evaluation of higher education courses. Of those who had trained in the UK, Claudia Sarrico had experience of assessing and managing the performance of public services in the fields of education and higher education, having published extensively in this area and having participated in several national and international projects. The former InspectorGeneral of Education, Carmo Clímaco, had been responsible for coordinating and managing various teams in the area of curriculum evaluation, educational success and school performance and had also published widely. Having launched the national evaluation of schools programme, she had coordinated the 'School Quality Observatory' as part of 'Education for All - 2000' (PEPT2000, 1994). Her engagement with international organisations involved in school evaluation is also worth highlighting: she had represented Portugal in the OECD's Indicators of Education programme (INES) and at the Standing International Conference of Inspectorates (SICI).

All of this experience informed the SEWG's approach to evaluation set out in its Final Report. It is specifically expressed in the best practice guidelines for school management, which emphasise the knowledge of evaluation models and theories of efficiency and efficacy. They place significant focus on 'quality' and on the qualitative aspects of pupils' learning as well as on optimisation and improvement. Likewise, great significance is accorded to statistical data on school performance: the Group stressed 'the need to furnish the external evaluators with more quantitative information about the school they are visiting' (ME 2006, p 6). It emphasises that the information selected by evaluation teams should be determined by evaluators' experience, but also by 'analysis of the literature regarding the factors that have an impact on school results and which are important for the evaluators to know in order to contextualise these results' (ME 2006, p 6). The reference framework drawn up by the Working Group which the evaluation teams expressly followed - is unequivocal on this point, specifying clearly its technical sources as well as the Inspectorate's participation in SICI and its knowledge and understanding of approaches taken in other European countries.

The Portuguese Inspectorate's participation in the Standing International Conference of Inspectorates (SICI, see chapter 6) testifies to its concern for international cooperation. SICI was established in 1995, bringing together 
inspection services from a number of European countries. Its activities focus on the exchange of experience, the development of partnership projects and the organisation of scientific and professional fora for the discussion of inspection methodologies and the professional training of inspectors. In introducing work planned for 2007, the Inspector-General draws attention to the SICI meeting to be held in Lisbon in November, in the context of the Portuguese Presidency of the European Union, as well as the organisation of a workshop on 'Inspecting for Equality in Early Childhood Services' by OFSTED []. The purpose of engagement of this kind was essentially that of knowledge exchange: to learn of other models and perspectives that might benefit the organization and performance of the IGE, and to gather information that might raise the profile of inspectors in relation to the challenges they faced (Barroso et al, 2007).

The Working Group's Final Report also refers to initiatives taken by inspectorates in other countries, specifically in Scotland and Northern Ireland (ME, 2006). Scotland's school self-evaluation manual 'How Good is our School' introduced new ideas that had been adapted to the Portuguese context, facilitating internal benchmarking and making comparison more stringent. The Report noted its 'huge popularity throughout Europe and the educational dynamism that has been brought about by giving schools the responsibility and the means to investigate their own quality' (ME, 2006, p 9). The Department of Education in Northern Ireland's document 'A process for self-evaluation', similarly sought to support and develop a self-evaluation culture in schools. It was appropriated by the SEWG in drawing attention to 'the way that evaluation is presented as part of the management of schools and the simplicity with which the different steps to be taken are described: the selection of key areas and the performance indicators, and specifically, the guidelines for schools to organise and prepare themselves for evaluation, so as to optimise the process in terms of overall performance, and minimise the negative effects that all evaluations may bring' (ME, 2006, p 9). It was notable for being part of 'a national strategy to improve education, which includes the evaluation of schools, assessment and improvement of the curriculum and educational services at different levels, improvement of the quality of initial and continuous teacher training and an overhaul of inspection methods so as to help guarantee quality' (ME, 2006, p 9).

In this way, the SEWG began to piece together elements of framework for assessing of the quality of Portuguese schools. The resulting model emerges from this confluence of projects and disciplines, professional training and practical know-how. Between them, the members of the team themselves had an advanced scientific and technical understanding of engineering as well as education, social policy as well as school inspection, R\&D as well as management and administration. The external vectors of influence on their work were of three kinds: international, sectoral and institutional.

The Effective School Self-Evaluation (ESSE) project run by SICI, important in assessing the consistency of self-evaluation by schools, is one example of international influence among others. More broadly, the very idea of evaluation is invariably cast in what is the international if anglophone language of new public management: the SEWG's insistence on quality, and its talk of 
'accountability', 'benchmarking' and 'best practice' all belong to a generalised discourse of 'modernisation', 'rationalisation' and 'efficiency'. In this way, what was international was also inter-sectoral: the evaluation methodology used in Portuguese schools drew heavily on the European Foundation for Quality Management (EFQM) model, which is far from specific to education. As the Working Group reported, 'The 'European Pilot Project for Self-Evaluation of Schools' and its subsequent developments, the 'Total Quality Management' model or the EFQM... has functioned as the framework for other self-evaluation developments such as the Common Evaluation Framework (CEF), both in public administration and in private organizations' (ME, 2006, p 8-9). Both sources of influence, however, only nourished a developing institutional appreciation of evaluation in Portuguese education. At the national level, an earlier school evaluation programme (the 'School Integrated Evaluation') had been carried out by IGE from 1999 to 2002 . The work of the SEWG was not conducted ex novo, but is best thought of as a point of arrival in an on-going process that began in the late 1990s and continued to be developed and reworked in subsequent programmes of Portuguese inspection.

The SEWG acted as a vessel for the reception and circulation of different kinds of knowledge about evaluation, a point of access for the international studies and institutional practices which had been variously internalised by the group members through their professional experience. It might be said that the logic of evaluation served as a technocratic common denominator of individuals and countries, disciplines and perspectives. But its work was also an active process of synthesis and consolidation which shaped borrowings and inheritances to immediate purposes. What was imported from elsewhere was also reinvented in the process (Rogers 2003).

For in selecting from the scientific and international literature on school effectiveness, the SEWG placed particular emphasis on the qualitative aspects of pupils' learning, on the strategic aspects of optimisation and improvement, and on the professional know-how of inspectors, principals and teachers. It openly distanced itself from more metric models of evaluation, which it treated as no more than management instruments. As the group outlined, in its concern for accountability it focussed primarily on educational partners' search for fundamental answers about their performance, and less so on access to statistical data, which is in any case now widely available (see Barroso et al., 2007).

In Freeman and Sturdy's terms (chapter one), the members of the SEWG brought almost incalculable embodied knowledge to the tables at which they drafted and deliberated the detail of the Inspector-General's new evaluation policy for schools. They drew on a reservoir of related documents, reporting academic research and describing projects and programmes used in Portugal and elsewhere. A vast array of knowledge, in both embodied and inscribed form, provided the cognitive resource for their decisions. But still they took decisions, made choices, had ideas that coalesced into the evaluation strategy they set out as if - as Garfinkel has it - for 'another first time'. The moment of policy formulation, that is to say, is an enactment of a particularly significant kind. 


\section{The evaluation process}

But how is all this knowledge applied and used in the conduct of evaluations? We note that knowledge is a local phenomenon (Sturdy, 2008, p 1), structured within a specific context, and holding significance for social actors based on their purposes and objectives in that context. It follows that our interest is not solely in knowledge 'inputs' - in this case, the knowledge incorporated in the instruments of evaluation - but in the way that knowledge is processed in the course of the various activities that go to make up an evaluation. Here again, our sense of the various and successive forms that knowledge takes - embodied, inscribed and enacted - provides the necessary heuristic for understanding the micro-transactions inherent in planning and carrying out an evaluation. It is used to describe how the 'policy technology' of indicators and guidelines, meetings, interviews and reports moulds the way relevant actors, including inspectors, principals, teachers and pupils themselves, come to think of education and schooling and to perform their assigned roles in the regulatory apparatus.

As specified by the Inspectorate-General, the work of an evaluator involves: '(i) participation in the initial training and a preparation session for each team member; (ii) full-time presence for two or three days in school visits; (iii) handing in of contributions to the team leader for the report, as well as a suggested classifications; (iv) presentation of comments and suggestions about the versions of the report and replies to points made; and (v) participation in the annual evaluation of the process' (IGE/ME, 2009, p 12). Evaluation teams are made up of two inspectors and one evaluator external to the inspectorate - a senior higher education teacher or researcher, a retired primary or secondary school teacher, or even a professional from another area (see IGE/ME, 2009, p. 12). The external member is considered a precious resource that enables a crossing of viewpoints, leading to better identification of different aspects of the school that might be improved. While inspectors themselves are experienced in integrated evaluation, the role of the external assessor was deemed particularly important in supporting a new generalist approach. As an inspector pointed out,

"(W)e had been recruited from different areas, but the idea in terms of the transformation of inspection was that the inspector should be more generalist. Hence, as well as the training we had - we did a postgraduate qualification in Inspection at the Catholic University with its own specific curriculum - we also had to have a lot of practical training on the various tasks of Inspection, from the disciplinary area to financial issues. This gave us a lot of know-how in terms of 'general knowledge'".1

Of course, this generalist character makes the work as a whole more demanding:

"One of the fundamental differences is that we have to master various aspects of the school... everything that contributes to the school's being as it is. We used to work more in one area, like pedagogical or financial. Now it's the

\footnotetext{
${ }^{1}$ Interview, 17 June 2010.
} 
entirety of the process that counts. It requires us to know and to be inside the various areas of the school."2

\section{preparation}

Each school visit is structured in three phases: preparation, a site visit and the final report. During the preparation phase, the evaluation team focuses on a set of documents provided by the school in order to give shape to their subsequent investigation (table 3.1). These include the Educational Project, the Curricular Project, the Annual Activity Plan and a set of internal regulations as well as the Internal Evaluation/Self-Evaluation Reports. The 'School Presentation Document' requested from the school by the Inspectorate is also submitted to careful scrutiny. In preparing this document, the school is invited to follow the format suggested on the IGE website. These guidelines specify the content and layout described as necessary to offer 'a global image of the school and its context', while also outlining the 'development priorities and targets, strategies to achieve them, results obtained and reflections they give rise to'. ${ }^{3}$

\section{ME/IGE documents:}

Dissemination leaflet on the External Evaluation of Schools and the global reports of the external evaluation programme;

Pilot project report (School Evaluation Working Group, 2006)

Annual Reports 2006-2007, 2007-2008 and 2008-2009

Reference framework for the evaluation of schools and groups 2009-2010

Topics for school presentations 2009-2010

Assessment scale 2009-2010

Schedule and organisation of visits

School documents:

Curricular project

Education project

Internal regulations

'School Profile' (statistical data, socio-economic framework)

Self-Evaluation Report

Table 3.1: Documents used in the External Evaluation of Schools, 2009-2010

Each evaluator reads the school documentation, drawing up charts and categories from the information supplied:

"We dedicated the first day to reading the documents, each one of us individually, and we arranged a meeting on the second day to prepare the questions. This second day was basically about exchanging thoughts on the

\footnotetext{
${ }^{2}$ Interview, 17 June 2010.

${ }^{3}$ www.ige.min-edu.pt
} 
documents we had received and what questions they gave rise to. We used a chart, an Excel spread sheet, in accordance with the Reference Framework". ${ }^{4}$

This stage of the process depends on good information management to filter the data, in order that only that which is relevant to the assessment is considered. There must be a "separation of the useful from the accessory..., as there could be two or three thousand pages of documentation". ${ }^{5}$

From the school's perspective, producing the material required entails a collective analysis of the institution's structural documents and hence its identity. This is intended to lead to reflection on the life of the school and its evolution "in the last three to four years and the kind of thinking and conclusions drawn within the scope of the self-evaluation". ${ }^{6}$ However, in our case study, the degree of involvement in this activity by senior and middle management differed greatly. The former viewed the initiative as a resource to enable it to

"have a more in-depth perspective, given that what is registered in writing is a positive or negative appraisal of that year, but then in subsequent years the information ends up getting lost. If school issues were more documented and statistically processed so that afterwards they could be reviewed on a three or five-year basis, it would be much easier".7

Middle management, on the other hand, pointed to drawbacks, providing comments that were more impressionistic than factual: "It seems to me that they evaluate according to what happened in the past... If they really gather other information from the Management, over the years, then perhaps this has some influence and may bias the evaluation from the start". ${ }^{8}$ Among the wider school community, meanwhile, there was greater acknowledgement of a learning process: "The fact we are building the educational project helps us to rethink what we want in a more conscious manner... the evaluation contributed to this reflection". ${ }^{9}$ However the evaluation project is understood, the school's selfimage must be condensed into a text of maximum 30,000 characters.

\section{the site visit}

Each school visit last for two to three days and includes a presentation by the school leadership with questions from the external evaluation team, an overview of facilities, and interviews with different panels. It begins with a meeting between the school leadership and the evaluators in order to reach an overall appraisal of the documents and initial information provided, while identifying what further data might be necessary for their validation. This meeting can take different forms; it can proceed discreetly or be accorded significant focus by the school.

\footnotetext{
4 Interview, 17 June 2010.

5 Interview, 17 June 2010.

${ }^{6}$ Interview, 17 June 2010.

${ }^{7}$ Interview, 30 June 2010.

8 Interview, 30 June 2010.

${ }^{9}$ Interview, 30 June 2010.
} 
Inspection of a school's facilities includes observing its different services in operation, while asking "a question or two to a pupil or a staff member we come across...". ${ }^{10}$ It is not intended as a formal visit, but an opportunity to get a snapshot of the everyday life of the school, in order to develop a broader sense of its pedagogy and organization and to enable better judgments to be made about its different domains.

"(W)e look at safety, in specific spaces such as the library and the laboratories to see the equipment and check the safety regulations are complied with... At times, we are accompanied by the Head and call on one or two teachers. If the visit coincides with lessons we take the chance to ask the pupils about laboratory experiments, whether they do them themselves or if they just observe the teacher doing them. We also visit the gymnasium and check the condition of things, and we talk to a Physical Education teacher".11

After that, a series of interviews is held, first with the school leadership, then with the self-evaluation team.

The interviews are conducted in panels organised by the school and are thought of as "the essential method used by the external evaluation team to talk with the educational community and to gather information".12 Here, too, the process is informed but not determined by a standard template: "We worked on the basis of the theoretical framework and then, depending on the reality of each school, we made the issues more concrete, trying to establish how they acted. Therefore, there is an adaptation of the theoretical framework to each particular school."13 One of the coordinators stressed, similarly, that "There was another point on which we did not have a very clear notion, which was not only associated with negative outcomes, but also with the question of 'quality of success', which was a concept that we had not, and we did not interpret the same way".14

The kind of embodied, experiential knowledge brought to bear in meetings and interview panels generally lacks the degree of formal coherence and consistency more characteristic of the document. Indeed, it is closely articulated with the subjective desires, aspirations and anxieties of the actors involved: "There is always a bit of nervousness, but we felt we were in a working environment that was receptive and collaborative," one manager said. ${ }^{15}$ A coordinator noted the different styles of evaluators: "Some raised issues in an inquisitorial manner, and we felt that there was a trick question' somewhere, which I think was unnecessary. But there were also other attitudes, more constructive, and I think that's also important". 16

\footnotetext{
10 Interview, 17 June 2010.

11 Interview, 17 June 2010.

12 Interview?

13 Interview, 17 June 2010.

14 Interview, 30 June 2010.

15 Interview, 30 June 2010.

16 Interview, 30 June 2010.
} 
On the other hand, evaluators spoke of difficulties managing the larger panels: "Sometimes you have to deal with the fact that one panel member or another wants to 'lead' and therefore we must try to give everyone the opportunity to participate'. ${ }^{17}$ Another said that "I have already found some situations where people were, to begin with, rather suspicious. They exhibited a certain aggressiveness but then the situation loosened up".18 Different panels behave in different ways: "In some you can see that there has been almost no exchange of ideas about what goes on. Others have what they are going to say so meticulously prepared that we can see that messages had been passed between them about what they had to say...".19 The pupil panels, by contrast, are often rich and spontaneous "in defending their school and the fact they are there to show what they do. It can be seen from that that they feel in step with the school and that they view us as outsiders and people who need to be impressed". ${ }^{20}$ As one of the last panels, the interview with teachers is very important "because it allows us to cross-check a lot of the information we have collected and, in the end, this panel gives us the opportunity to confirm and clarify doubts". 21

\section{reporting}

The final stage of the evaluation process is the drafting and presentation of a report, based on the template set up by the SEWG and adapted in accordance with the documentary and interview material gathered from the school. The draft draws on notes taken during the panels, "and then we cross with each other to confirm all the information".22 This is team work involving the participation of all its members in the making of the document: "We are particularly careful to do an internal reading to check that the ideas are clear, that there are no typos, that there is coherence". ${ }^{23}$ In synthesising different personal writing styles, a standard vocabulary and terminology is used, derived from the theoretical framework, which places the school at the centre of the analysis. Moreover, each report should be "properly grounded", 24 based on arguments supported by evidence. The evaluators' appraisal is essentially mapped out "in terms of its internal coherence and the classifications". 25

In reputational terms, the significance of the report to the school is difficult to underestimate:

"In our case, things went well. It [the final report] is published for everyone to see. If it had gone badly... the public image of the school would have been questioned. If it had been unfair, that would have been catastrophic, and a huge frustration for anyone giving everything to the school".

\footnotetext{
17 Interview, 17 June 2010.

18 interview?

19 Interview, 17 June 2010.

20 Interview, 17 June 2010.

21 Interview, 17 June 2010.

${ }^{22}$ Interview, 17 June 2010.

23 Interview, 17 June 2010.

24 Interview, 17 June 2010.

25 Interview, 17 June 2010.
} 
This reputational risk is a function of the new knowledge and information generated about the school in the process of evaluating it, of course, but is also predicated on that knowledge being made mobile - and public - in inscribed, documentary form. Perhaps more positively, "(W)e are [now] more concerned to disseminate and illustrate what we do, and that used to be confined within the four walls of the school. Using the platform of the school, we have a blog, we are finally publicizing our activity, with parents and with local authorities".26

\section{knowledge in the evaluation process}

In this way, through its programme for the self-evaluation of schools, the Ministry has standard frame of reference for thinking about the quality of public schools in Portugal. Indeed what it has standardised perhaps even more significantly is the assumption that the quality and performance of schools is something that should be thought about. It has created a standard set of information about each school that makes one comparable with another and that makes each accountable for its performance in relation to others. What has been established appears rigid - a framework, an architecture or structure for the assessment and management of performance - and yet our case study is lit throughout by a sense of fluidity and uncertainty, both in the creation of the programme of evaluation and in its implementation.

In developing its new policy instrument, the Ministry, through its InspectorateGeneral, has mobilised an array of knowledge about what evaluation is, but also about what education is and what a school should be and do. It has drawn on the various disciplinary backgrounds of the experts involved in its Working Group, on the experiments developed in other European countries, and on its own experience of precursor and pilot initiatives. It invokes the everyday expertise of the school principal and her management team, of teachers, pupils and support staff. It gathers academic and policy papers, statistics, guidelines and rulebooks, job descriptions, memoranda and reports. It requires all of these bodies of knowledge to be brought into relation with each other, in deliberation in meetings and in the consolidation and synthesis entailed in writing reports. In this way, the evaluation programme serves as an elaborate device by which different kinds of knowledge and expertise are funneled into and through the school. Our enduring sense is one of the inherent instability and mobility of that knowledge: the system is one of seemingly perpetual motion.

For all its technocratic aspect, evaluation endorses the knowledge embodied in persons: in chief inspectors who know what's really going at SICI, in teachers who know how their school really runs, in pupils who know what they really do in and out of class. They may know what's in the documents, but they also know what's not in them. What is interesting, too, is the way embodied knowledge emerges in encounters and conversations with others, as well as with texts and artefacts. In the course of evaluations, moments of interaction are crucial for both the reconstruction of meaning and the production of new meaning, enabling the team to grasp the dynamics of and thinking behind the school. As one

${ }^{26}$ Interview, 30 June 2010. 
evaluator explained: "This happens, for example, in a school where we found nothing in terms of innovation... through the intervention of a member of the community we were immediately given a vision that could not be gleaned from reading any of the documents, about the innovative aspects of that school". ${ }^{27}$

The documents matter, of course. As the evaluation team points out: "we always work based on guidelines. The guidelines are usually produced by the central services". ${ }^{28}$ The guidelines draw on myriad others, including academic papers, policy statements and reports, and other guidelines. They generate, in turn, the school's account of itself in its rules and regulations, the minutes of its meetings, the job descriptions of its management team and the reports and other statements it writes specifically for the evaluation. In this way, the selfevaluation of a school is realised not in individual documents, such as its Profile or its Final Report, but in the network of texts of which they form a part. And not only in texts and documents, but in artefacts and buildings, too - in the Gymnasium the evaluation team visits, in the configuration of the playground, in the arrangement of chairs and desks in a classroom.

Knowledge is enacted, of course, in the conduct of every meeting, in the drafting of every document, and in all the actions which follow from them. Working group discussions and panel interviews alike follow one course or another on the basis of what its participants know - for 'knowledge is what we think with' (Barnes, 1995, p 91). But what they know is called up in the instant of needing to know it, and deployed or not according to its holder's judgement of its validity and appropriateness in immediate circumstances. In the case of the External Evaluation of Schools, enacted knowledge emerges in a succession of fora: as the school management team drafts its Profile, in the inspectorate briefing sessions where the evaluation is planned; in the meetings and interviews carried out during the visit; in the drafting of the Final Report and the further discussions which follow from it. It is this that gives us a sense that the most fundamental effect of evaluation is to put knowledge into motion. For all the new inscriptions it produces in documents, statements and reports, the most significant effect of evaluation is the obligatory enactment and re-enactment of knowledge it entails. Evaluation, at least in the form we have studied here, doesn't necessarily require those evaluated to know anything new, but it does require them to know what they know: to express and articulate, revise and revisit all of the taken for granted knowledge without which a school could not function and would not exist.

The evaluation process appears as a chain of enactments, of responding to questions and writing things down, almost always in collaboration and consultation with others. The enactment which is evaluation is an inescapably collective process. It may be this that accounts for the ambiguity it seemed to hold for its participants: the evaluation was variously constrained but creative, oppressive but liberating, routine but unpredictable. It is this uncertainty that we explore in the last part of this chapter.

\footnotetext{
27 Interview, 17 June 2010.

28 Interview, 17 June 2010.
} 


\section{regulation and re-enactment}

The purpose of evaluation, as a regulatory instrument - is to make actors newly aware of what they do. This is especially true of self-evaluation, which is designed to inculcate a heightened degree of reflective self-awareness among managers and professionals. One inspector revealed that "We're not going to control, we will not tell the school what to do, but to see how the school works... our intention is to get people to show what they do, to question them and lead them to reflect."29 Another expected to see "a reflection of the school... how the school has reflected on their reality and what is being done to improve the results, because this is what is intended." And the evidence of our case study is that evaluation does indeed work in this way. As panel members acknowledged, "the questions they asked made us reflect on things which we often don't realise are being carried out in the school... It makes us reflect more together about school procedures and ways of running the school".30 Some said that the effect of the IGE's intervention had been to alert them to aspects of their work they had not previously valued, including "the work of cooperation that we have been involved in and which has been intensifying" and "the articulation that now we have with the pre-school and other cycles." 31

It is crucial to the regulatory function of evaluation that with increased reflection goes an increased sense of responsibility. As one of our respondents commented,

"It was above all an added concern, because we are aware of the work that we are doing; we have been at this school for a long time and we have done a lot of work. Now we feel that anything that is not right will be written down and published as a label that says the school is not a good one... this is an added responsibility... When we left the panel we were a little anxious, but afterwards we had the sensation that we were in fact doing a lot, only we don't question it". 32

This is burdensome, even troubling to some, as when they spoke of the 'nervousness,' 'concern' and 'anxiety' brought by the added sense of accountability they felt the evaluation process had vested on them.

Whether reflexivity and responsibility bring any increase in autonomy is difficult to determine and that is perhaps because, in a sociological sense, it is undetermined. The flow of knowledge in and through the school is carefully channelled by the formal requirements of the evaluation. This 'cognitive scripting' leaves actors with the freedom to act, though it requires to them to think in very specific ways, that is in ways which will give appropriate content to the categories according to which they will be evaluated. A school or any part of it may be innovative, exceptional, unique or simply different, if it can justify those qualities in terms set by the evaluation.

\footnotetext{
${ }^{29}$ Interview, 17 June 2010.

30 Interview, 30 June 2010.

31 Interview, 30 June 2010.

32 Interview, 30 June 2010.
} 
Something similar holds at the different stages of development and implementation of the evaluation programme we have reviewed here. In the national and international context in which it worked, there was nothing which required the Schools Evaluation Working Group to design its programme one way or another. What it proposed was specific to education in Portugal, but recognisable to its peers in other sectors and countries. The programme for the external evaluation of schools was new, but normal. That is to say that the knowledge it comprised, like all knowledge, was subject to an almost infinitely extended process of social validation. In turn, the enactments of evaluation - the draftings, discussions and deliberations which take place in schools - are reenactments of those enactments made by the Working Group which set the frame of reference. They unfold sequentially, over time, as documents are drafted and redrafted, successive meetings are held and different stages of the process are completed. A school learns what it is by learning how to describe itself in the terms set by the evaluation. In this sense, the process of evaluation process is also a process of education.

Accounts and assessments of school performance are achieved only through repeated rehearsal of the cognitive script set by the SEWG. Each enactment of it is no more - and no less - than a re-enactment of an external frame of reference. Its precepts are reproduced necessarily imperfectly, but they are necessarily reproduced. As a governance mechanism, self-evaluation has a tolerance or affordance which more direct or bureaucratic regulation does not. It harnesses the specific dynamic of knowledge which is both locally specific and generally or socially validated, and it is this which makes it seem at once both unpredictable and inescapable. 